\title{
Evaluation of Leukocyte-Endothelial Interactions in Retinal Diseases
}

\author{
Akitaka Tsujikawa $^{a}$ Yuichiro Ogura ${ }^{b}$ \\ a Department of Ophthalmology and Visual Sciences, Kyoto University Graduate School of Medicine, Kyoto, and \\ ${ }^{b}$ Department of Ophthalmology and Visual Science, Nagoya City University Graduate School of Medical Sciences, \\ Nagoya, Japan
}

\section{Key Words}

Leukocytes · Retinal endothelium · Scanning laser ophthalmoscopy

\begin{abstract}
Purpose: We reviewed various methodologies for studying leukocyte-retinal endothelial interactions in vivo, and summarized the information obtained from studies employing these methods. Procedures: Fluorescence dye-enhanced scanning laser ophthalmoscopy facilitates study of leukocyte-cell interactions in the retinal microcirculation. Results: Various methods such as adaptive optics scanning laser ophthalmoscopy (AO-SLO), acridine orange digital angiography, and intravital microscopy provided evidence of the mechanisms of leukocyte recruitment in the retina and of their importance in the pathogenesis of various retinal diseases. Conclusions: Leukocyte behavior can be easily examined in the retina in vivo because the optical media is transparent. SLO substantially contributes to visualizing leukocyte-endothelial interactions in retinal vessels, although most of the methods employing SLO could only be used for animal studies. AO-SLO noninvasively demonstrates the movement of each leukocyte in the parafoveal capillaries in humans. Message: AO-SLO could be useful in investigating the leukocyteretinal endothelial interactions in various diseases in humans.

Copyright $\odot 2011$ S. Karger AG, Basel
\end{abstract}

\section{Introduction}

Blood flow in the blood vessels is determined by various factors, such as vessel diameter, blood pressure, vascular network structure, viscosity, and the rheological properties of blood [1]. A previous study has investigated the effects of blood rheology to disturbances in the microcirculation, mainly on erythrocyte dynamics [2]. Subsequent studies have employed intravital microscopy in order to demonstrate the pivotal role of leukocytes in microcirculatory flow [3]. Leukocytes are likely to be involved in flow disturbances in the microcirculation of various organs under physiological and pathological conditions [4].

Leukocytes also play a central role in the pathogenesis of the various inflammatory or noninflammatory diseases [4-8]. Accumulated leukocytes may produce various cytokines and proteases, resulting in enlargement of the inflammation, or they may function in the host defense against foreign bodies [9]. In the large vessels, leukocytes mainly flow along the central stream. Even in microvessels, leukocytes exhibit limited interactions with endothelial cells under physiological conditions. Leukocyte-endothelial interactions are essential for leukocyte recruitment in a targeted organ, and these interactions are elaborately regulated by a multi-step cascade involving various adhesion molecules [10-13]. Many animal studies have been conducted using intravital microscopy, allowing us to

\section{KARGER}

Fax +41613061234

E-Mail karger@karger.ch

www.karger.com
(C) 2011 S. Karger AG, Basel

0030-3755/12/2272-0068\$38.00/0

Accessible online at:

www.karger.com/oph
Akitaka Tsujikawa, MD

Department of Ophthalmology and Visual Sciences

Kyoto University Graduate School of Medicine

Sakyo-ku, Kyoto 606-8507 (Japan)

Tel. +81 75751 3260, E-Mail tujikawa@kuhp.kyoto-u.ac.jp 


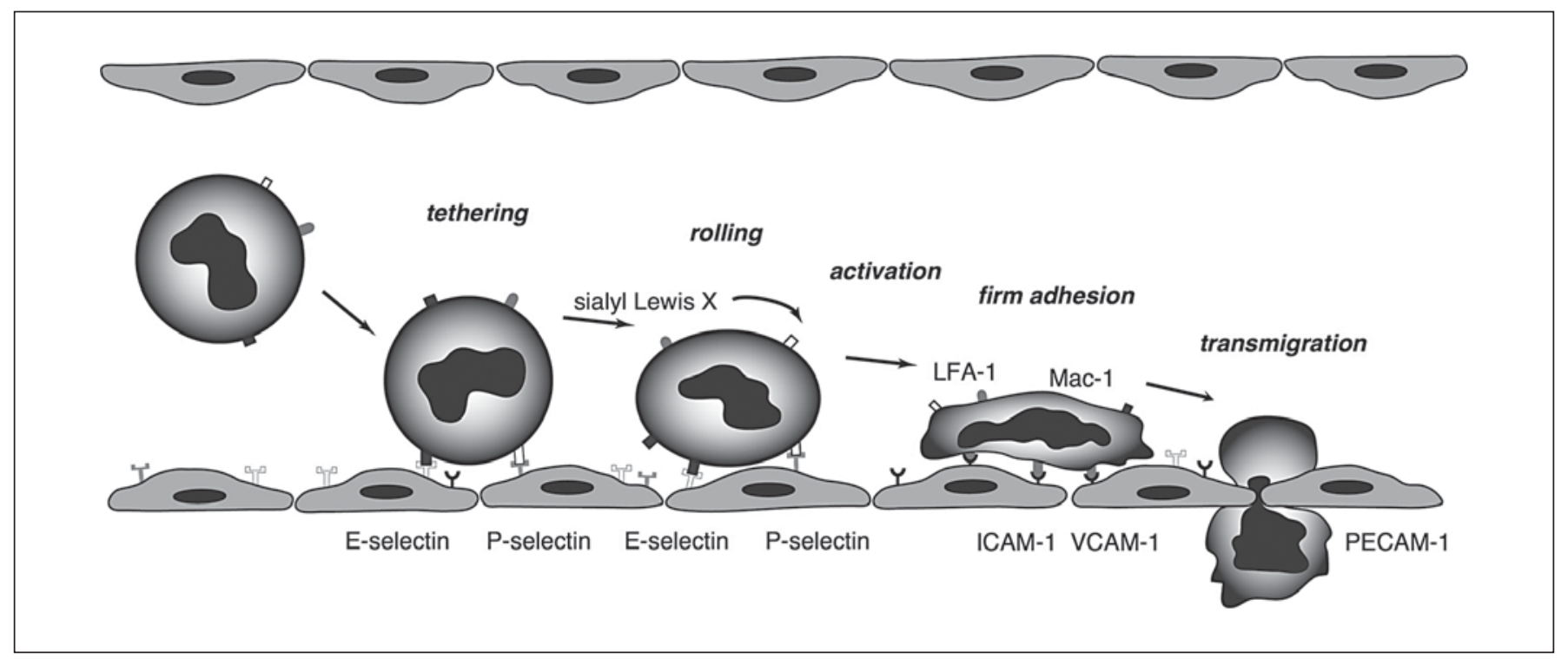

Fig. 1. Multistep process of leukocyte-endothelial interactions. It is essential for freely circulating leukocytes to interact with endothelial cells in order to accumulate in the target tissue. These interactions consist of multiple steps such as tethering, rolling, activation, firm adhesion, and transmigration. Each step is regulated elaborately by various adhesion molecules expressed by the leukocytes and endothelial cells.

study leukocyte-endothelial interactions in vivo, and these studies have contributed to our understanding of the delicate regulation of various organs [4-8].

Previous studies have revealed the importance of leukocytes in various retinal diseases [14]; however, leukocyte behavior in the retinal microcirculation could not be adequately studied due to the lack of appropriate methods. Scanning laser ophthalmoscopes can capture a series of confocal fundus images at a video rate, and, when combined with fluorescence dyes, they enable the evaluation of leukocyte-endothelial interactions in the retinal microcirculation [15]. Novel methodologies have been used to obtain an increasing body of information with regard to the mechanisms of leukocyte recruitment in the retina, choroid, and the vitreous cavity [16]. In this paper, we review various methodologies in the study of leukocyte-retinal endothelial interactions in vivo, and summarize the information obtained from previous experimental studies employing these methods.

\section{Leukocyte-Endothelial Interactions}

\section{Adhesion Molecules}

Leukocyte-endothelial interactions are elaborately regulated with the aid of adhesion molecules expressed by the leukocytes and endothelial cells of the retinal blood vessels $[10,13]$. Selectins are a family of 3 carbohydrate-recognizing transmembrane molecules - E-selectin, $\mathrm{P}$-selectin, and L-selectin. The former 2 are expressed on activated endothelial cells, and the latter is constitutively expressed on leukocytes. Integrins are $\alpha \beta$-heterodimers that recognize extracellular matrix cell surface glycoproteins. All leukocytes express $\beta 2$ integrins [Mac1 (CD11b/CD18), LFA-1 (CD11a/CD18), p150, and p95 (CD11c/CD18)]. The ligands of the integrins expressed on the endothelial cell surface are ICAM-1, ICAM-2, and ICAM-3, which belong to the immunoglobulin superfamily.

\section{Multistep Process of Leukocyte-Endothelial Interactions}

In order that freely circulating leukocytes accumulate in the target tissue, they must interact with vascular endothelial cells. These interactions involve multiple steps (tethering, rolling, activation, firm adhesion, and transmigration), and are mainly observed in postcapillary venules but not in arterioles (fig. 1) [10, 13, 17].

In postcapillary venules, leukocytes tend to move closer to the endothelial surface than in the central bloodstream. This is caused by a passive rheological phenomenon. The first interaction between leukocytes and en- 
dothelial cells is termed tethering, which is mediated by selectins. This initial intermittent interaction reduces the speed of the circulating leukocyte and facilitates the subsequent step of rolling. Previous experimental studies using intravital microscopy have elucidated the mechanism of leukocyte rolling. Reduction in their flow speed following the initial intermittent interactions allows leukocytes to intimately interact with the endothelial cells. This step, termed rolling, is mediated by E- and P-selectins expressed on the activated endothelium. While leukocytes interact with the endothelial cells, they become activated by chemoattractants produced by the activated endothelial cells, such as interleukin- 8 and platelet-activating factor. During rolling, some activated leukocytes firmly adhere to the endothelial cells with Mac-1 (CD11b/ CD18) and LFA-1 (CD11a/CD18). In this process, chemoattractant receptors are stimulated, making the cell more rigid and enabling it to migrate. The leukocytes that adhere to the endothelial cells then transmigrate into the tissue with PECAM-1 (CD31) and $\beta 2$ integrins.

\section{Methodology}

Thus far, researchers have introduced various methods for investigating leukocyte-retinal endothelial interactions in vivo, and these methods have been applied to physiological and pathological conditions. However, all the methods suggested and implemented this far have limitations.

\section{Fluorescence-Labeled Leukocyte Angiography}

When fluorescein sodium is infused into the vein, circulating leukocytes are stained with fluorescein sodium. However, due to the intense fluorescence in the serum, it is difficult to detect the leukocytes [16]. To reduce the background fluorescence, isolated donor leukocytes that are labeled in vitro are infused to the recipients and studies with scanning laser ophthalmoscopy (SLO). Thus far, studies have used different fluorescence agents such as fluorescein sodium, fluoroisothiocyanate (FITC), calcein-AM, and carboxyfluorescein diacetate (CFDA) for leukocyte labeling [18]. Since the absorption peak and emission wavelength of these agents are near to the corresponding values of fluorescein sodium, the originally equipped filters for fluorescein angiography can be used for the analysis.

Many studies have used fluorescein sodium for leukocyte labeling [19-22]. Blood was first incubated with sodium fluorescein in vitro, following which it was centrifuged and the buffy coat containing leukocytes and plate- lets was separated. These labeled cells were then infused into recipient animals. SLO with an argon laser was used to visualize the labeled leukocytes circulating in the fundus, which enables the investigation of leukocyte-endothelial interactions in the retina. Since the safety of fluorescein sodium is well established, several investigators have used this dye for human studies [22]. This method poses a limitation as the labeled leukocytes are contaminated by many platelets that also are stained with fluorescein sodium. Moreover, the leukocytes may be activated during isolation or labeling, and such activated leukocytes may exhibit unphysiological behavior after infusion. Other investigators have used FITC or calcein-AM to label isolated leukocytes [23-25]. These dyes have only been used in animal studies and have not been used in human studies [26]. Calcein-AM is reported to be nontoxic and has no effect on cell adhesion [27].

CFDA is another possible fluorescence agent for leukocyte labeling [28]. CFDA itself is not fluorescent but is converted to carboxyfluorescein by intracellular esterase, whose fluorescence properties are similar to those of fluorescein sodium. After CFDA is converted into carboxyfluorescein, the dye remains within the cell [29]. CFDA enables visualization of leukocytes in the retinal circulation for $>30 \mathrm{~min}$. However, the usage of CFDA is also limited to animal experiments.

\section{Acridine Orange Digital Angiography}

Acridine orange has been widely used as a fluorescence probe for nucleic acids in studies using histochemistry, flow cytometry, and cytochemistry. The dye emits green fluorescence when it binds with double-stranded nucleic acids (DNAs). The spectral properties of acridine orange-DNA complexes are almost similar to those of fluorescein sodium. Retinal images were generated by SLO with the aid of argon blue laser and a regular emission filter for fluorescein angiography. Following intravenous injection of acridine orange solution, leukocytes are selectively stained among circulating blood cells because only leukocytes have double-stranded DNA.

Leukocyte dynamics are recorded at the video rate and can be studied frame by frame. Because the nuclei of vascular endothelial cells are also stained, this method allows investigation of leukocyte-endothelial interactions along the retinal veins, such as rolling and firm adhesion in vivo (fig. 2) [30-32]. In addition, 30 min after the infusion, the fluorescence of the circulation leukocytes and endothelial cells fades and only the leukocytes accumulated in the retinal microcirculation can be visualized (fig. 3). The main limitation of this technique is 
Fig. 2. Acridine orange digital angiography. a Immediately after acridine orange infusion. Leukocytes are stained selectively among the circulating blood cells. The nuclei of vascular endothelial cells are also stained. Leukocytes in the capillaries (arrows) moved slowly, making brief stops; leukocytes in the veins (arrowheads) moved at a higher velocity. b Many rolling leukocytes can be observed among freeflowing leukocytes along the major retinal veins (arrowheads). No rolling leukocytes were present in the major retinal arteries. Some leukocytes adhered to the venous wall (arrows). c Two leukocytes can be seen rolling along the venous wall (arrowheads), and one was adhered to the venous wall (arrow). This figure was previously published in Stroke [85].

Fig. 3. Acridine orange digital angiography. Leukocytes accumulated in the retina observed as fluorescent dots at $30 \mathrm{~min}$ after acridine orange injection. A small number of leukocytes were present in control rats (a). Increasing numbers of leukocytes accumulated at $4 \mathrm{~h}$ (b) and $12 \mathrm{~h}$ (c) after reperfusion in vehicle-treated rats. The number of leukocytes peaked $24 \mathrm{~h}$ after reperfusion (d). Significant reduction in leukocyte accumulation was observed in tacrolimus-treated rats at $12 \mathrm{~h} \mathrm{(e)} \mathrm{and} 24$ $\mathrm{h}(\mathbf{f})$ after reperfusion. This figure was previously published in Stroke [85].
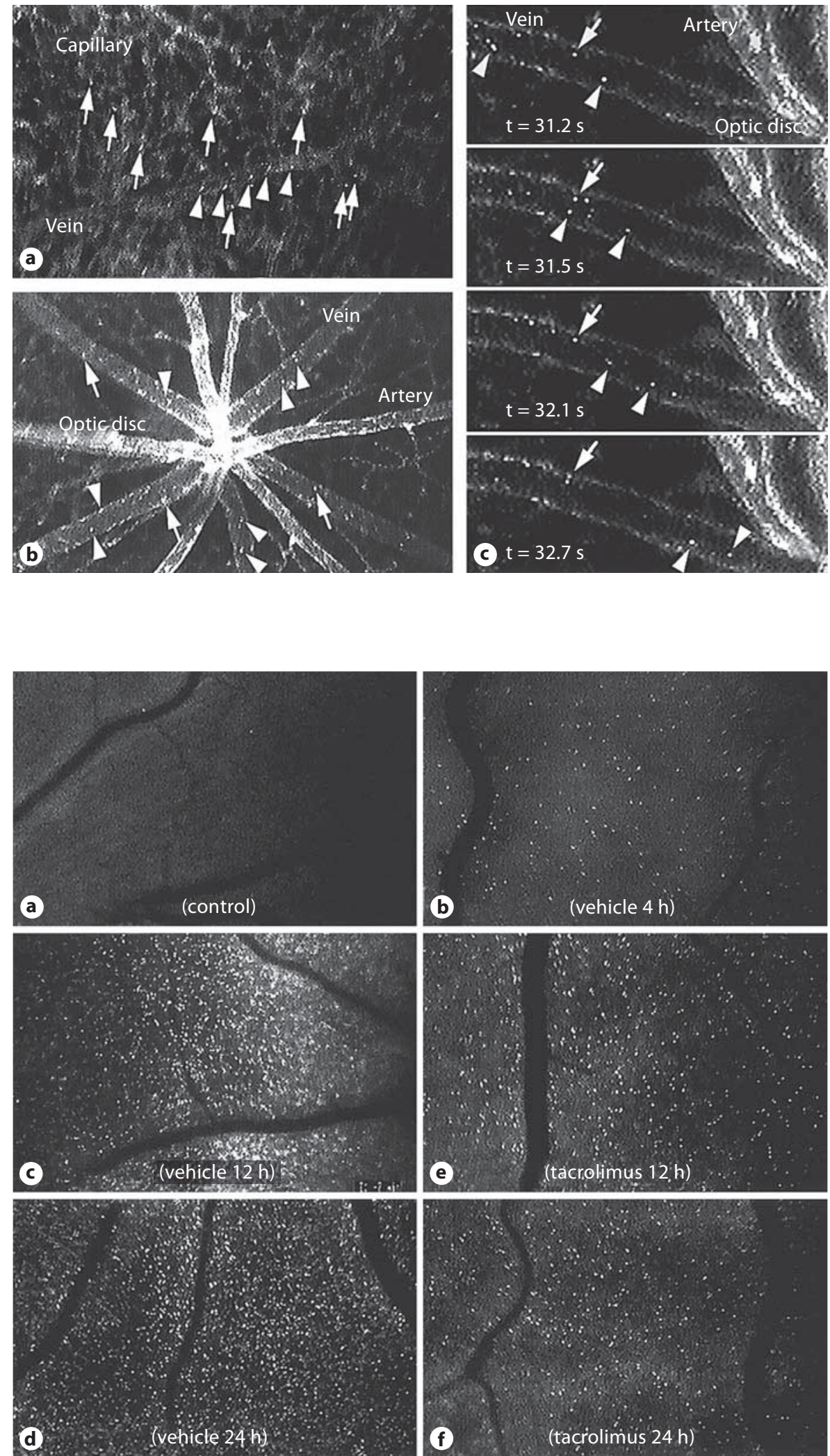

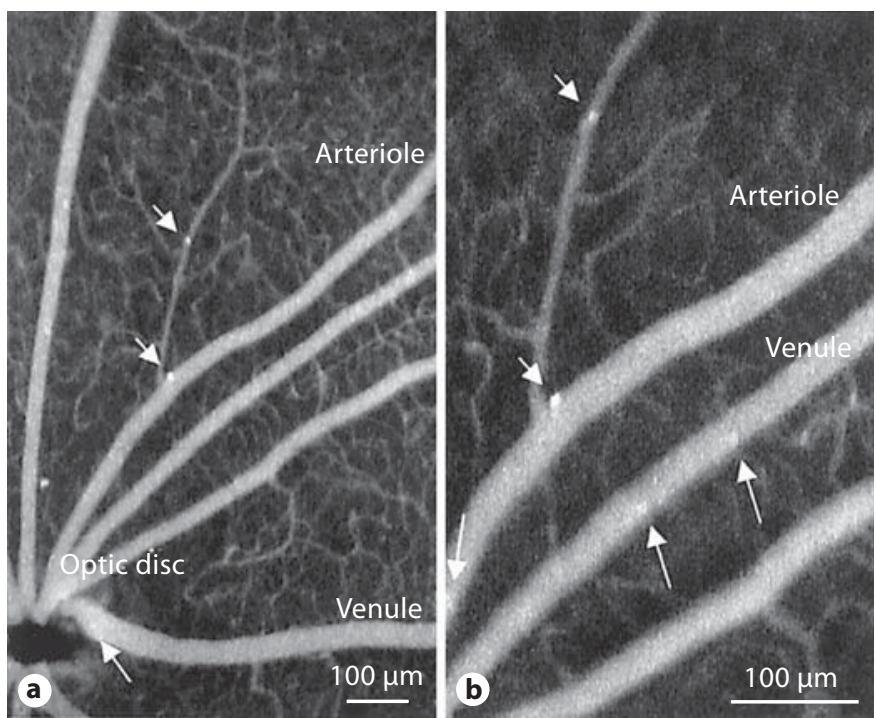

Fig. 4. Leukocyte angiography with CFDASE. a CFDASE fundus image of a rat with diabetes $\left(40^{\circ}\right.$ field setting) shows that leukocytes adhere not only to venules (long arrow) but also to arterioles (short arrows). b The same fundus image in a $20^{\circ}$ field setting. While many leukocytes were seen to flow through the retinal vessels (long arrows), 2 adhered to the walls of retinal arterioles (short arrows). The direction of the blood flow was used to distinguish arterioles from venules. This figure was previously published in The FASEB Journal [33].

that acridine orange has carcinogenic effects and can only be used in experimental animals. In addition, it is suggested that acridine orange causes a proportion of neutrophils to spontaneously convert from rolling to immobilization mediated by $\beta 2$-integrin [27]. Acridine orange may cause some functional changes in the leukocytes.

\section{Leukocyte Angiography with Carboxyfluorescein}

Diacetate Succinimidyl Ester

Carboxyfluorescein diacetate succinimidyl ester (CFDASE) is another dye that can enable visualization of leukocyte-retinal endothelial interactions in vivo by intravenous infusion of the dye. Similar to CFDA, CFDASE itself is not a fluorescence compound, but is converted to CFDASE within the cells, and has fluorescence properties similar to fluorescein sodium [5]. After the infusion, circulating leukocytes and endothelial cells can be visualized using SLO [33]. Immediately after the infusion, the contrast of circulating leukocytes is not as strong as those stained with acridine orange. However, leukocytes that adhere to the retinal vessels can be visual- ized clearly after the fluorescein levels in the bloodstream have decreased (fig. 4). This method is only applied to animal studies.

\section{Intravital Microscopy}

Intravital epifluorescence microscopy is widely used to study the hemodynamics of various organs. When this technique is used to investigate retinal microcirculation, it is necessary to cancel the strong refractivity of the cornea. Anesthetized mice were placed under the objective and then examined. The refractive power of the cornea was counteracted by placing a glass slide on a ring surrounding the globe $[34,35]$. The head was supported so that the iris was in a plane perpendicular to the axis of illumination. Epi-illumination was delivered through dichroic filters on a mercury lamp. The extracted donor leukocytes and erythrocytes were labeled separately in vitro with fluorescence dyes with different spectral properties, such as FITC and rhodamine-6G. After the fluorescence-labeled blood cells were infused in the recipient mice, the movement of blood cells was visualized using intravital microscopy. An intravital microscope can be equipped with multiple filters and strong illumination, so that switching the filter will facilitate concomitant visualization of elements labeled differently, thus permitting the simultaneous evaluation of leukocyte and erythrocyte movement.

\section{Blue Field Simulation Technique}

The blue field entoptic phenomenon is the perception of entoptic images observed against a bright blue illumination and is caused by the movement of leukocytes in the macular capillaries of the observer [36, 37]. Previous studies have noninvasively evaluated the velocity of leukocytes and the hemodynamics of retinal capillaries by matching the subject's entoptic images with the leukocyte motion simulated on a computer screen. This noninvasive method can be applied to human studies [38, 39]; however, it is limited to the perifoveal capillary network and is subjective. It is impossible to study the behavior of each leukocyte.

\section{Adaptive Optics AO-SLO}

Adaptive optics SLO (AO-SLO) is an SLO-equipped adaptive optics technology that generates high-resolution and high-contrast retinal images by correcting ocular aberrations [40-42]. Recent studies have used AO-SLO to visualize individual retinal photoreceptors [43]. In addition, the videos obtained by AO-SLO can be used to noninvasively observe leukocyte movement in parafoveal 
Fig. 5. Leukocyte movement in AO-SLO. a Montage of AO-SLO images of the macula of the healthy subject. b Five consecutive frames (taken from the inset in a) showing a white particle (circled) moving through a capillary. Figure courtesy of Dr. Akihito Uji.
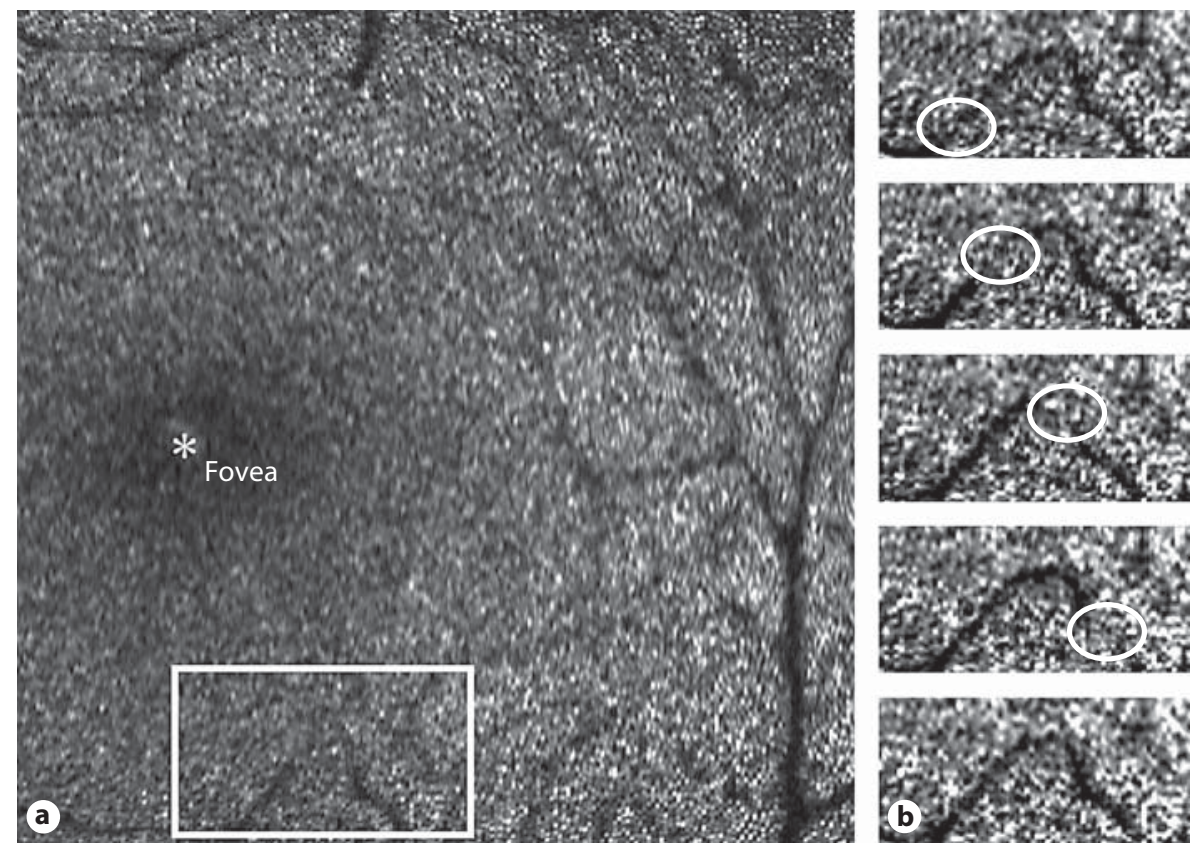

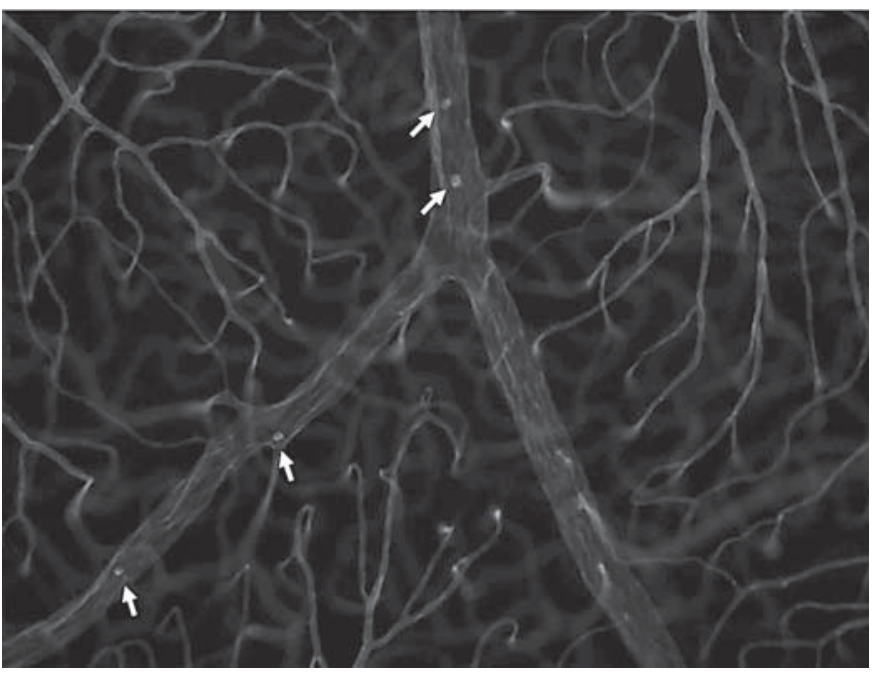

Fig. 6. Lectin staining highlights the adherent leukocytes within the retinal vasculature. The adherent leukocytes are visible in the retinal veins of a rat with diabetes (arrows). Figure courtesy of Dr. Kenji Yamashiro.

capillaries, which can be visualized as high-intensity particles moving in the dark vessels [44-46]. A frame-byframe analysis aids in evaluating the precise movement of each leukocyte. The results can be interpreted as follows: leukocytes circulating within the parafoveal capillaries allow the laser to penetrate and reach the photore- ceptors beneath the vessels, facilitating detection of the reflected light from the photoreceptors at locations corresponding to the presence of leukocytes (fig. 5). This method is similar to the blue field simulation technique [37]. The evaluation is limited to the parafoveal capillaries. However, this method enables objective analysis of the movement of each leukocyte in the retinal vessels, and it can also be applied to human studies. Thus far, the applications of this method, which has so far only been used in normal subjects, are expected to expand to various pathological conditions. Further, this method can potentially contribute to the study of leukocyte dynamics in the human retina.

\section{Lectin Labeling of Adherent Leukocytes in the Retina}

It is impossible to evaluate leukocyte movement in histological specimens of the retina; however, leukocytes that adhere to the retinal vessel can be studied [14, 47]. Concanavalin A lectin was used to label adherent leukocytes and vascular endothelial cells. After perfusion with phosphate-buffered saline to remove erythrocytes and non-adherent leukocytes, the experimental animals were fixed with paraformaldehyde and glutaraldehyde and stained with rhodamine- or FITC-coupled concanavalin A $[33,48,49]$. The retina was carefully removed, and flat mounts were prepared. The adherent leukocytes were observed under a fluorescence microscope (fig. 6). 


\section{Leukocyte-Endothelial Interactions in Pathological Conditions}

\section{Physiological Conditions}

Nishiwaki et al. [30] used acridine orange leukocyte angiography and reported the behavior of each leukocyte in the physiological retina of monkeys. Although each leukocyte flows freely in retinal veins, some exhibit plugging in the retinal capillaries. Under physiological conditions, only few leukocyte-endothelial interactions were present; further, there were no rolling leukocytes in the main retinal arteries and veins. While the reason for this is unclear, organ specificity might explain the limited leukocyte-cell interactions. Alternatively, since the blood pressure within the retinal vein is relatively high in order to resist intraocular pressure, the difference in the blood pressure between the intraocular and extraocular veins could contribute to the increased shear stress in the retinal veins, resulting in less frequent interactions. In another paper, Nishiwaki et al. obtained images of the leukocyte movement in the murine retina at higher magnification [31]. Each leukocyte flowed in the capillaries with a deformation of shape [32].

\section{Diabetes Mellitus}

There is increasing evidence suggesting the role of leukocytes in the pathogenesis of diabetic retinopathy [50]. McLeod et al. [47] studied patients with diabetes and reported elevated neutrophil levels in retinal vessels, together with elevated ICAM-1 expression. Persistent lowgrade inflammation from the upregulation of cytokines and other inflammatory mediators, and mechanical blockage of retinal capillaries due to plugged leukocytes are considered to contribute to the damage of retinal endothelial cells [51, 52].

It has been reported that the nature of leukocytes itself is changed in patients with diabetes. In diabetes, the deformability and membrane fluidity of leukocytes are reported to be decreased [53]. In addition, more protein molecules are adsorbed on the surfaces of leukocyte membranes by glycosylation, resulting in decreased cell deformability [54]. These changes in the rigidity of leukocytes contribute to leukocyte plugging in the retinal capillaries as observed in experimental animals with diabetes [55]. In addition, leukocytes of individuals with diabetes show greater ability to adhere to the vascular endothelium [56]. In conditions of hyperglycemia, neutrophils exhibit increased adhesion to retinal endothelial cells $[57,58]$.

Miyamoto et al. [59] reported increased leukostasis in both streptozotocin-induced diabetic rats and spontane- ously diabetic Otsuka Long-Evans Tokushima Fatty rats. In the former case, increased retinal leukostasis was observed as early as 3 days after the induction of diabetes [60]. In addition, increased leukostasis was accompanied by a corresponding increase in leakage from the retinal vasculature. Fluorescein angiography revealed that these leukocytes were correlated with blockage of capillaries, resulting in local retinal non-perfusion. In these rats, increased leukostasis was accompanied by an upregulated expression of retinal ICAM-1 mRNA [60]. Moreover, the increases in leukostasis and in vascular permeability were inhibited by systemic administration of antiICAM-1 antibody [60]. These results indicate that the elevation of ICAM-1 on retinal endothelial cells may be essential for the retinal changes observed in early diabetes $[50,51]$.

Another study has reported that leukocytes of patients with diabetes express higher levels of the $\alpha$-integrin subunits CD11a and CD11b and the $\beta$-integrin subunit CD18 [61]. In addition, administration of anti-CD18 or antiICAM-1 antibodies was found to inhibit retinal leukostasis, in parallel with reduction of endothelial cell apoptosis $[33,62]$. One study performed using CD18 or ICAM-1 knockout mice found that leukocyte adhesion in retinal vessels due to diabetes mellitus was substantially reduced with reduction in endothelial injury and breakdown of the blood-retinal barrier [63].

Based on these findings, it can be said that chronic hyperglycemia due to diabetes causes increased ICAM-1 and integrin expression on retinal endothelial cells and leukocytes, respectively, leading to increased leukostasis in the retinal microvessels [51]. The increased leukocytes would contribute to the endothelial cell damage with increased leakage. These leukocyte-endothelial interactions may be a possible target of inhibition in diabetic retinopathy [64-78].

\section{Ischemia-Reperfusion Injury}

After transient ischemia, leukocytes accumulate in the reperfused tissue and cause tissue injury by blocking the blood flow or by producing hydrogen peroxide $[9,79]$. Tsujikawa et al. [80] studied the leukocyte-endothelial interaction after transient retinal ischemia. After ischemia was induced for $60 \mathrm{~min}$, rolling leukocytes were first observed along the venous walls at $4 \mathrm{~h}$ after reperfusion. The number of rolling leukocytes increased and peaked at $12 \mathrm{~h}$, and decreased to control levels at $96 \mathrm{~h}$. Subsequent leukocyte accumulation increased with time and peaked at $24 \mathrm{~h}$.

Nishijima et al. [81] have reported that the P-selectin and ICAM-1 gene expression levels in the retina after 60 
min of ischemia were upregulated at 12 and $24 \mathrm{~h}$ after reperfusion. In addition, attenuation of P-selectin or ICAM1 by systemic administration of monoclonal antibodies successfully reduced the leukocyte-endothelial interactions in the postischemic retina, consequently suppressing tissue damage [82]. On the basis of the results of these experiments, many investigators have studied various agents that can attenuate tissue damage by suppressing leukocyte-endothelial interactions in the postischemic retina. Antithrombin III [83, 84], tacrolimus (FK506) [85], argatroban (direct thrombin inhibitor) [86], statin [87, 88], Rho-associated protein kinase inhibitor [89], superoxide dismutase [90], thalidomide [91], selectin ligands/inhibitor (SKK-60060) [92], triamcinolone acetonide [93], ischemic preconditioning [94, 95], platelet depression [81], and $17 \beta$-estradiol [96] are reported to reduce leukocyte accumulation in the postischemic retina and thereby reduce neural damage.

However, the time course of leukocyte-endothelial interactions in the postischemic retina considerably differs from that in other organs. Similar studies in the dorsal skinfold chamber model of hamsters, in mice, and in the mesentery of rats have reported that rolling leukocytes peak 30 min after reperfusion and almost subside $24 \mathrm{~h}$ after reperfusion [8]. This difference could be attributed to the specificity of the retina subjected to ischemia reperfusion injury [7].

\section{Macular Edema}

Sometimes physicians encounter cases of macular edema after panretinal photocoagulation for diabetic retinopathy. Leukocyte velocities in the retinal capillaries were reported to have significantly decreased immediately after photocoagulation [97]. Nonaka et al. [98] hypothesized that inflammatory reactions after photocoagulation may be involved in the pathogenesis of macular edema, and they studied leukocyte-endothelial cell interactions and vascular permeability after partial scatter laser photocoagulation. Scatter laser photocoagulation caused significant inflammatory leukocyte-endothelial interactions not only in the photocoagulated but also in the untreated retina. In the nonphotocoagulated retina, the number of leukocytes rolling along the major retinal veins increased after photocoagulation and peaked at $12 \mathrm{~h}$. Leukocyte accumulation in the untreated half of the retina increased and peaked at $24 \mathrm{~h}$. In addition, the expressions of P-selectin and ICAM-1 genes were significantly upregulated [99]. These leukocyte-endothelial interactions were attenuated with posterior sub-tenon administration of triamcinolone acetonide [100] or sys- temic administration of thrombin inhibitor [99]. The inhibitory effect of triamcinolone acetonide on the macular edema after photocoagulation is consistent with clinical observations [101].

\section{Interferon-Associated Retinopathy}

Guyer et al. [102] described interferon-associated retinopathy, which produces focal retinal ischemia, such as cotton-wool spots, capillary nonperfusion, and inner retinal hemorrhage. While the pathogenesis of interferon-associated retinopathy is unclear, diabetes mellitus, hypertension, retinal arterial sclerosis, and anemia were reported to be risk factors. Its fundus manifestation is similar to Purtscher's retinopathy, which is thought to be caused by retinal circular disturbances induced by activated leukocytes [103]. Nishiwaki et al. [104] reported adherent leukocytes and leukocytes rolling on the retinal venous wall in interferon $\alpha-2 b$-treated rats. Leukocytes trapped in the retinal microcirculation were increased dose-dependently by intravenous administration of interferon $\alpha-2 b$. In another report, interferon- $\alpha$ induced leukocyte entrapment in retinal microcirculation was reduced by simultaneous administration with prednisolone, platelet-activating factor receptor antagonist, or superoxide dismutase [105]. Leukocytes stimulated with interferons may exhibit active interactions with retinal capillaries of veins, resulting in focal retinal ischemia.

\section{Uveitis}

Endotoxin-induced uveitis (EIU) is induced by injection of lipopolysaccharides derived from Gram-negative bacteria into footpads of experimental animals, and is frequently used to generate experimental models of uveitis. Miyamoto et al. [106] have studied the leukocyte-endothelial interactions in the retinae of EIU rats. In arteries and veins, EIU-induced vasodilatation gradually occurred and increased to the maximum level at $24 \mathrm{~h}$. Leukocytes began to roll along the venous walls at $4.5 \mathrm{~h}$ after LPS injection and reached peaked at $12 \mathrm{~h}$. Leukocytes were observed to infiltrate the vitreous cavity from $24 \mathrm{~h}$ after induction and peaked at $48 \mathrm{~h}$. In parallel with the leukocyte rolling, the gene expression levels of P-selectin increased in the retina of EIU rats [107]. Moreover, administration of monoclonal antibodies to P-selectin at EIU induction successfully reduced the flux of leukocyte rolling and subsequent infiltration into the vitreous cavity. However, when P-selectin was inhibited after the induction, the leukocyte infiltration and inflammatory vasodilatation was not suppressed. Suzuma et al. [108] as- 
sayed the levels of E-selectin gene expression in the retina of EIU rats. Selective inhibition of E-selectin significantly blocked cellular infiltration into the aqueous humor; further, inhibition of both P- and E-selectin almost abrogated cellular infiltration. Based on these experiments, many investigators studied agents that could suppress leukocyte-endothelial interactions in uveitis. Selectin inhibitor [109], TNF- $\alpha$ inhibitor [110], diphenhydramine (histamine H1 receptor) [111], and antithrombin III [112] were found to reduce leukocyte-endothelial interactions in the retinal veins in EIU rats. Hamada et al. [113] reported leukocyte behavior in the retina in experimental autoimmune uveoretinitis (EAU) [114]. Various uveitis models have been used to obtain increasing information on the molecular regulation of leukocyte recruitment [115]. Leukocyte-retinal endothelial interactions during uveitis are elaborately regulated by several adhesion molecules, cytokines, and chemokines [116-122]. Reviews of recent studies would aid in further elucidating these mechanisms [123-125].

\section{Conclusion}

In nature, leukocyte behavior can be easily examined in the retina in vivo because the optical media is transparent. SLO substantially contributes to visualizing leukocyte-endothelial interactions in retinal vessels. However, most of the methods that employ SLO could only be used for animal studies. In addition, SLO is no longer commercially available. Recently, some investigators developed AO-SLO for the observation of retinal blood flow. AO-SLO noninvasively demonstrates the movement of each leukocyte in the parafoveal capillaries in humans. Thus far, AO-SLO has been applied only for investigating leukocyte movement in the retinae of normal subjects. However, it might contribute to our understanding of the leukocyte-retinal endothelial interactions in various diseases in humans.

\section{Disclosure Statement}

The authors have no financial interest in the materials or devices mentioned in this article.

\section{References}

1 Schmid-Schonbein H: Critical closing pressure or yield shear stress as the cause of disturbed peripheral circulation? Acta Chir Scand Suppl 1976;465:10-19.

-2 Schmid-Schonbein H, Grebe R, Heidtmann $\mathrm{H}$ : A new membrane concept for viscous $\mathrm{RBC}$ deformation in shear: spectrin oligomer complexes as a Bingham-fluid in shear and a dense periodic colloidal system in bending. Ann N Y Acad Sci 1983;416:225254.

-3 Bagge U, Amundson B, Lauritzen C: White blood cell deformability and plugging of skeletal muscle capillaries in hemorrhagic shock. Acta Physiol Scand 1980;108:159-163.

-4 Engler RL, Schmid-Schonbein GW, Pavelec RS: Leukocyte capillary plugging in myocardial ischemia and reperfusion in the dog. Am J Pathol 1983;111:98-111.

5 Suematsu M, DeLano FA, Poole D, Engler RL, Miyasaka M, Zweifach BW, Schmid-Schonbein GW: Spatial and temporal correlation between leukocyte behavior and cell injury in postischemic rat skeletal muscle microcirculation. Lab Invest 1994;70:684-695.

-6 Romson JL, Hook BG, Kunkel SL, Abrams GD, Schork MA, Lucchesi BR: Reduction of the extent of ischemic myocardial injury by neutrophil depletion in the dog. Circulation 1983;67:1016-1023.
7 Szaflarski J, Burtrum D, Silverstein FS: Cerebral hypoxia-ischemia stimulates cytokine gene expression in perinatal rats. Stroke 1995;26:1093-1100.

-8 Nolte D, Lehr HA, Messmer K: Adenosine inhibits postischemic leukocyte-endothelium interaction in postcapillary venules of the hamster. Am J Physiol 1991;261:H651-H655.

-9 Smith JK, Grisham MB, Granger DN, Korthuis RJ: Free radical defense mechanisms and neutrophil infiltration in postischemic skeletal muscle. Am J Physiol 1989; 256:H789-H793.

10 Ley K: Molecular mechanisms of leukocyte recruitment in the inflammatory process. Cardiovasc Res 1996;32:733-742.

11 Greenwood J, Howes R, Lightman S: The blood-retinal barrier in experimental autoimmune uveoretinitis: leukocyte interactions and functional damage. Lab Invest 1994;70:39-52.

12 Greenwood J, Wang Y, Calder VL: Lymphocyte adhesion and transendothelial migration in the central nervous system: the role of LFA-1, ICAM-1, VLA-4 and VCAM-1. Immunology 1995;86:408-415.

13 Granger DN, Kubes P: The microcirculation and inflammation: modulation of leukocyte-endothelial cell adhesion. J Leukoc Biol 1994;55:662-675.
14 Schroder S, Palinski W, Schmid-Schonbein GW: Activated monocytes and granulocytes, capillary nonperfusion, and neovascularization in diabetic retinopathy. Am J Pathol 1991;139:81-100.

15 Webb RH, Hughes GW, Delori FC: Confocal scanning laser ophthalmoscope. Appl Opt 1987;26:1492-1499.

16 Masaoka N, Nakaya K, Koura Y, Ohsaki M: Hemodynamic changes in two patients with retinal circulatory disturbances shown by fluorescein angiography using a scanning laser ophthalmoscope. Retina 2001;21:155160

17 Jalkanen S: Leukocyte-endothelial cell interaction and the control of leukocyte migration into inflamed synovium. Springer Semin Immunopathol 1989;11:187-198.

18 Hossain P: Scanning laser ophthalmoscopy and fundus fluorescent leucocyte angiography. Br J Ophthalmol 1999;83:1250-1253.

19 Kim J, Yang Y, Shin B, Cho C: Visualization and flow of platelets and leukocytes in vivo in rat retinal and choroidal vessels. Ophthalmic Res 1997;29:374-380.

20 Yang Y, Kim S, Kim J: Visualization of retinal and choroidal blood flow with fluorescein leukocyte angiography in rabbits. Graefes Arch Clin Exp Ophthalmol 1997;235:27-31. 
-21 Le Gargasson JF, Paques M, Guez JE, Boval B, Vicaut E, Hou X, Grall Y, Gaudric A: Scanning laser ophthalmoscope imaging of fluorescein-labelled blood cells. Graefes Arch Clin Exp Ophthalmol 1997;235:56-58.

22 Paques M, Boval B, Richard S, Tadayoni R, Massin P, Mundler O, Gaudric A, Vicaut E: Evaluation of fluorescein-labeled autologous leukocytes for examination of retinal circulation in humans. Curr Eye Res 2000;21:560565.

-23 Fillacier K, Peyman GA, Luo Q, Khoobehi B: Study of lymphocyte dynamics in the ocular circulation: technique of labeling cells. Curr Eye Res 1995;14:579-584.

24 Dagkalis A, Wallace C, Xu H, Liebau S, Manivannan A, Stone MA, Mack M, Liversidge J, Crane IJ: Development of experimental autoimmune uveitis: efficient recruitment of monocytes is independent of CCR2. Invest Ophthalmol Vis Sci 2009;50:4288-4294.

-25 Xu H, Manivannan A, Goatman KA, Liversidge J, Sharp PF, Forrester JV, Crane IJ: Improved leukocyte tracking in mouse retinal and choroidal circulation. Exp Eye Res 2002; 74:403-410.

- 26 Horan PK, Melnicoff MJ, Jensen BD, Slezak SE: Fluorescent cell labeling for in vivo and in vitro cell tracking. Methods Cell Biol 1990;33:469-490.

-27 Abbitt KB, Rainger GE, Nash GB: Effects of fluorescent dyes on selectin and integrinmediated stages of adhesion and migration of flowing leukocytes. J Immunol Methods 2000;239:109-119.

28 Hossain P, Liversidge J, Cree MJ, Manivannan A, Vieira P, Sharp PF, Brown GC, Forrester JV: In vivo cell tracking by scanning laser ophthalmoscopy: quantification of leukocyte kinetics. Invest Ophthalmol Vis Sci 1998;39:1879-1887.

-29 Price EA, Coombe DR, Murray JC: A simple fluorometric assay for quantifying the adhesion of tumour cells to endothelial monolayers. Clin Exp Metastasis 1995;13:155-164.

- 30 Nishiwaki H, Ogura Y, Kimura H, Kiryu J, Honda Y: Quantitative evaluation of leukocyte dynamics in retinal microcirculation. Invest Ophthalmol Vis Sci 1995;36:123-130.

- 31 Nishiwaki H, Ogura Y, Kimura H, Kiryu J, Miyamoto K, Matsuda N: Visualization and quantitative analysis of leukocyte dynamics in retinal microcirculation of rats. Invest Ophthalmol Vis Sci 1996;37:1341-1347.

-32 Kimura H, Kiryu J, Nishiwaki H, Ogura Y: A new fluorescent imaging procedure in vivo for evaluation of the retinal microcirculation in rats. Curr Eye Res 1995;14:223-228.

- 33 Joussen AM, Murata T, Tsujikawa A, Kirchhof B, Bursell SE, Adamis AP: Leukocytemediated endothelial cell injury and death in the diabetic retina. Am J Pathol 2001;158: 147-152.

-34 Tadayoni R, Paques M, Gaudric A, Vicaut E: Erythrocyte and leukocyte dynamics in the retinal capillaries of diabetic mice. Exp Eye Res 2003;77:497-504.
5 Paques M, Tadayoni R, Sercombe R, Laurent P, Genevois O, Gaudric A, Vicaut E: Structural and hemodynamic analysis of the mouse retinal microcirculation. Invest Ophthalmol Vis Sci 2003;44:4960-4967.

36 Loebl M, Riva CE: Macular circulation and the flying corpuscles phenomenon. Ophthalmology 1978;85:911-917.

37 Riva CE, Petrig B: Blue field entoptic phenomenon and blood velocity in the retinal capillaries. J Opt Soc Am 1980;70:12341238.

38 Grunwald JE, Piltz J, Patel N, Bose S, Riva $\mathrm{CE}$ : Effect of aging on retinal macular microcirculation: a blue field simulation study. Invest Ophthalmol Vis Sci 1993;34:3609-3613.

39 Fallon TJ, Chowiencyzk P, Kohner EM: Measurement of retinal blood flow in diabetes by the blue-light entoptic phenomenon. Br J Ophthalmol 1986;70:43-46.

40 Liang J, Williams DR, Miller DT: Supernormal vision and high-resolution retinal imaging through adaptive optics. J Opt Soc Am A Opt Image Sci Vis 1997;14:2884-2892.

-41 Roorda A, Romero-Borja F, Donnelly Iii W, Queener H, Hebert T, Campbell M: Adaptive optics scanning laser ophthalmoscopy. Opt Express 2002;10:405-412.

42 Talcott KE, Ratnam K, Sundquist SM, Lucero AS, Lujan BJ, Tao W, Porco TC, Roorda A, Duncan JL: Longitudinal study of cone photoreceptors during retinal degeneration and in response to ciliary neurotrophic factor treatment. Invest Ophthalmol Vis Sci 2011;52:2219-2226.

-43 Ooto S, Hangai M, Sakamoto A, Tsujikawa A, Yamashiro K, Ojima Y, Yamada Y, Mukai $\mathrm{H}$, Oshima S, Inoue T, Yoshimura N: Highresolution imaging of resolved central serous chorioretinopathy using adaptive optics scanning laser ophthalmoscopy. Ophthalmology 2010;117:1800-1809.

44 Martin JA, Roorda A: Direct and noninvasive assessment of parafoveal capillary leukocyte velocity. Ophthalmology 2005;112: 2219-2224.

45 Martin JA, Roorda A: Pulsatility of parafoveal capillary leukocytes. Exp Eye Res 2009; 88:356-360.

46 Uji A, Hangai M, Ooto S, Yoshimura N, Imamura $\mathrm{H}$ : Hemodynamic analysis of parafoveal capillaries using AOSLO. Invest Ophthalmol Vis Sci 2011;52:E-Abstract 4475.

-47 McLeod DS, Lefer DJ, Merges C, Lutty GA: Enhanced expression of intracellular adhesion molecule-1 and P-selectin in the diabetic human retina and choroid. Am J Pathol 1995; 147:642-653.

48 Gotte M, Joussen AM, Klein C, Andre P, Wagner DD, Hinkes MT, Kirchhof B, Adamis AP, Bernfield M: Role of syndecan-1 in leukocyte-endothelial interactions in the ocular vasculature. Invest Ophthalmol Vis Sci 2002;43:1135-1141.
49 Garland RC, Sun D, Zandi S, Xie F, Faez S, Tayyari F, Frimmel SA, Schering A, Nakao S, Hafezi-Moghadam A: Noninvasive molecular imaging reveals role of PAF in leukocyteendothelial interaction in LPS-induced ocular vascular injury. FASEB J 2011;25:12841294.

-50 Miyamoto K, Ogura Y: Pathogenetic potential of leukocytes in diabetic retinopathy. Semin Ophthalmol 1999;14:233-239.

51 Adamis AP, Berman AJ: Immunological mechanisms in the pathogenesis of diabetic retinopathy. Semin Immunopathol 2008;30: 65-84.

52 Kern TS: Contributions of inflammatory processes to the development of the early stages of diabetic retinopathy. Exp Diabetes Res 2007;2007:95103.

53 Vermes I, Steinmetz ET, Zeyen LJ, van der Veen EA: Rheological properties of white blood cells are changed in diabetic patients with microvascular complications. Diabetologia 1987;30:434-436.

54 Masuda M, Murakami T, Egawa H, Murata $\mathrm{K}$ : Decreased fluidity of polymorphonuclear leukocyte membrane in streptozocin-induced diabetic rats. Diabetes 1990;39:466470.

55 Miyamoto K, Ogura Y, Kenmochi S, Honda Y: Role of leukocytes in diabetic microcirculatory disturbances. Microvasc Res 1997;54: 43-48.

56 Dosquet C, Weill D, Wautier JL: Molecular mechanism of blood monocyte adhesion to vascular endothelial cells. Nouv Rev Fr Hematol 1992;34(suppl):S55-S59.

57 Nozaki M, Ogura Y, Hirabayashi Y, Saishin Y, Shimada S: Enhanced expression of adhesion molecules of the retinal vascular endothelium in spontaneous diabetic rats. Ophthalmic Res 2002;34:158-164.

-58 Bullard SR, Hatchell DL, Cohen HJ, Rao KM: Increased adhesion of neutrophils to retinal vascular endothelial cells exposed to hyperosmolarity. Exp Eye Res 1994;58:641-647.

-59 Miyamoto K, Hiroshiba N, Tsujikawa A, Ogura Y: In vivo demonstration of increased leukocyte entrapment in retinal microcirculation of diabetic rats. Invest Ophthalmol Vis Sci 1998;39:2190-2194.

-60 Miyamoto K, Khosrof S, Bursell SE, Rohan R, Murata T, Clermont AC, Aiello LP, Ogura Y, Adamis AP: Prevention of leukostasis and vascular leakage in streptozotocin-induced diabetic retinopathy via intercellular adhesion molecule-1 inhibition. Proc Natl Acad Sci USA 1999;96:10836-10841.

61 Song H, Wang L, Hui Y: Expression of CD18 on the neutrophils of patients with diabetic retinopathy. Graefes Arch Clin Exp Ophthalmol 2007;245:24-31.

62 Barouch FC, Miyamoto K, Allport JR, Fujita $\mathrm{K}$, Bursell SE, Aiello LP, Luscinskas FW, Adamis AP: Integrin-mediated neutrophil adhesion and retinal leukostasis in diabetes. Invest Ophthalmol Vis Sci 2000;41:11531158. 
63 Joussen AM, Poulaki V, Le ML, Koizumi K, Esser C, Janicki H, Schraermeyer U, Kociok N, Fauser S, Kirchhof B, Kern TS, Adamis AP: A central role for inflammation in the pathogenesis of diabetic retinopathy. FASEB J 2004; 18:1450-1452.

64 Miyahara S, Kiryu J, Yamashiro K, Miyamoto K, Hirose F, Tamura H, Katsuta H, Nishijima K, Tsujikawa A, Honda Y: Simvastatin inhibits leukocyte accumulation and vascular permeability in the retinas of rats with streptozotocin-induced diabetes. Am J Pathol 2004;164:1697-1706.

- 65 Hattori T, Matsubara A, Taniguchi K, Ogura Y: Aldose reductase inhibitor fidarestat attenuates leukocyte-endothelial interactions in experimental diabetic rat retina in vivo. Curr Eye Res 2010;35:146-154.

- 66 Noda K, Nakao S, Zandi S, Engelstadter V, Mashima Y, Hafezi-Moghadam A: Vascular adhesion protein-1 regulates leukocyte transmigration rate in the retina during diabetes. Exp Eye Res 2009;89:774-781.

-67 Wang K, Wang Y, Gao L, Li X, Li M, Guo J: Dexamethasone inhibits leukocyte accumulation and vascular permeability in retina of streptozotocin-induced diabetic rats via reducing vascular endothelial growth factor and intercellular adhesion molecule-1 expression. Biol Pharm Bull 2008;31:15411546.

68 Mori F, Takahashi J, Nagaoka T, Abiko T, Hikichi T, Yoshida A: Inhibitory effect of bucillamine on the increased leukocyte entrapment in the retinal microcirculation of diabetic rats. Jpn J Ophthalmol 2006;50: 377-379.

-69 Ono R, Kakehashi A, Ito Y, Sugi N, Makino S, Kobayashi E, Hakamada Y, Takagi Y, Kitazume Y, Kawakami M: Effect of topical nipradilol on retinal microvascular leukocyte adhesion in diabetic rats. Ophthalmic Res 2006;38:270-273.

70 Mori F, Hikichi T, Nagaoka T, Takahashi J, Kitaya N, Yoshida A: Inhibitory effect of losartan, an AT1 angiotensin II receptor antagonist, on increased leucocyte entrapment in retinal microcirculation of diabetic rats. Br J Ophthalmol 2002;86:1172-1174.

-71 Huang H, Gandhi JK, Zhong X, Wei Y, Gong J, Duh EJ, Vinores SA: TNFalpha is required for late BRB breakdown in diabetic retinopathy, and its inhibition prevents leukostasis and protects vessels and neurons from apoptosis. Invest Ophthalmol Vis Sci 2011;52: 1336-1344.

-72 Leal EC, Martins J, Voabil P, Liberal J, Chiavaroli C, Bauer J, Cunha-Vaz J, Ambrosio AF: Calcium dobesilate inhibits the alterations in tight junction proteins and leukocyte adhesion to retinal endothelial cells induced by diabetes. Diabetes 2011;59:2637-2645.

-73 Hirano Y, Sakurai E, Matsubara A, Ogura Y: Suppression of ICAM-1 in retinal and choroidal endothelial cells by plasmid small-interfering RNAs in vivo. Invest Ophthalmol Vis Sci 2010;51:508-515.
4 Iliaki E, Poulaki V, Mitsiades N, Mitsiades CS, Miller JW, Gragoudas ES: Role of alpha 4 integrin (CD49d) in the pathogenesis of diabetic retinopathy. Invest Ophthalmol Vis Sci 2009;50:4898-4904.

75 Leal EC, Manivannan A, Hosoya K, Terasaki T, Cunha-Vaz J, Ambrosio AF, Forrester JV: Inducible nitric oxide synthase isoform is a key mediator of leukostasis and blood-retinal barrier breakdown in diabetic retinopathy. Invest Ophthalmol Vis Sci 2007;48: 5257-5265.

76 Matsuoka M, Ogata N, Minamino K, Matsumura M: Leukostasis and pigment epithelium-derived factor in rat models of diabetic retinopathy. Mol Vis 2007;13:1058-1065.

77 Chen P, Guo AM, Edwards PA, Trick G, Scicli AG: Role of NADPH oxidase and ANG II in diabetes-induced retinal leukostasis. Am J Physiol Regul Integr Comp Physiol 2007; 293:R1619-R1629.

78 Chen P, Scicli GM, Guo M, Fenstermacher JD, Dahl D, Edwards PA, Scicli AG: Role of angiotensin II in retinal leukostasis in the diabetic rat. Exp Eye Res 2006;83:1041-1051.

79 Mori E, del Zoppo GJ, Chambers JD, Copeland BR, Arfors KE: Inhibition of polymorphonuclear leukocyte adherence suppresses no-reflow after focal cerebral ischemia in baboons. Stroke 1992;23:712-718.

$\rightarrow 80$ Tsujikawa A, Ogura Y, Hiroshiba N, Miyamoto K, Kiryu J, Honda Y: In vivo evaluation of leukocyte dynamics in retinal ischemia reperfusion injury. Invest Ophthalmol Vis Sci 1998;39:793-800.

-81 Nishijima K, Kiryu J, Tsujikawa A, Miyamoto $\mathrm{K}$, Honjo $\mathrm{M}$, Tanihara $\mathrm{H}$, Nonaka $\mathrm{A}$, Yamashiro K, Katsuta H, Miyahara S, Honda Y, Ogura Y: Platelets adhering to the vascular wall mediate postischemic leukocyte-endothelial cell interactions in retinal microcirculation. Invest Ophthalmol Vis Sci 2004;45: 977-984.

82 Tsujikawa A, Ogura Y, Hiroshiba N, Miyamoto K, Kiryu J, Tojo SJ, Miyasaka M, Honda Y: Retinal ischemia-reperfusion injury attenuated by blocking of adhesion molecules of vascular endothelium. Invest Ophthalmol Vis Sci 1999;40:1183-1190.

83 Nishijima K, Kiryu J, Tsujikawa A, Honjo M, Nonaka A, Yamashiro K, Kamizuru H, Ieki Y, Tanihara H, Honda Y, Ogura Y: Inhibitory effects of antithrombin III on interactions between blood cells and endothelial cells during retinal ischemia-reperfusion injury. Invest Ophthalmol Vis Sci 2003;44:332-341.

84 Ozden S, Muftuoglu S, Tatlipinar S, Kaymaz F, Yildirim C, Yaylali V, Ozbay D: Protective effects of antithrombin III on retinal ische$\mathrm{mia} /$ reperfusion injury in rats: a histopathologic study. Eur J Ophthalmol 2005;15:367373.

85 Tsujikawa A, Ogura Y, Hiroshiba N, Miyamoto K, Kiryu J, Honda Y: Tacrolimus (FK506) attenuates leukocyte accumulation after transient retinal ischemia. Stroke 1998; 29:1431-1437, discussion 1437-1438.
86 Miyahara S, Kiryu J, Tsujikawa A, Katsuta H, Nishijima K, Miyamoto K, Yamashiro K, Nonaka A, Honda Y: Argatroban attenuates leukocyte- and platelet-endothelial cell interactions after transient retinal ischemia. Stroke 2003;34:2043-2049.

87 Miyaki K, Matsubara A, Nishiwaki A, Tomida K, Morita H, Yoshida M, Ogura Y: Pitavastatin attenuates leukocyte-endothelial interactions induced by ischemia-reperfusion injury in the rat retina. Curr Eye Res 2009; 34:10-17.

88 Honjo M, Tanihara H, Nishijima K, Kiryu J, Honda Y, Yue BY, Sawamura T: Statin inhibits leukocyte-endothelial interaction and prevents neuronal death induced by ischemia-reperfusion injury in the rat retina. Arch Ophthalmol 2002;120:1707-1713

89 Hirata A, Inatani M, Inomata Y, Yonemura N, Kawaji T, Honjo M, Tanihara H: Y-27632, a Rho-associated protein kinase inhibitor, attenuates neuronal cell death after transient retinal ischemia. Graefes Arch Clin Exp Ophthalmol 2008;246:51-59.

90 Szabo ME, Droy-Lefaix MT, Doly M, Carre C, Braquet P: Ischemia and reperfusion-induced histologic changes in the rat retina: demonstration of a free radical-mediated mechanism. Invest Ophthalmol Vis Sci 1991; 32:1471-1478.

-91 Aydogan S, Celiker U, Turkcuoglu P, Ilhan N, Akpolat N: The effect of thalidomide on vascular endothelial growth factor and tumor necrosis factor-alpha levels in retinal ischemia/reperfusion injury. Graefes Arch Clin Exp Ophthalmol 2008;246:363-368.

92 Matsubara A, Tomida K, Matsuda Y, Tamai K, Tashita A, Jomori T, Tsujikawa A, Ogura Y: Protective effects of selectin ligands/inhibitor (SKK-60060) against retinal ischemia-reperfusion injury. Exp Eye Res 2000; 71:283-293.

-93 Mizuno S, Nishiwaki A, Morita H, Miyake T, Ogura Y: Effects of periocular administration of triamcinolone acetonide on leukocyte-endothelium interactions in the ischemic retina. Invest Ophthalmol Vis Sci 2007; 48:2831-2836.

94 Ozbay D, Ozden S, Muftuoglu S, Kaymaz F, Yaylali V, Yildirim C, Tatlipinar S: Protective effect of ischemic preconditioning on retinal ischemia-reperfusion injury in rats. Can J Ophthalmol 2004;39:727-732.

95 Nonaka A, Kiryu J, Tsujikawa A, Yamashiro K, Nishijima K, Miyamoto K, Nishiwaki H, Honda Y, Ogura Y: Inhibitory effect of ischemic preconditioning on leukocyte participation in retinal ischemia-reperfusion injury. Invest Ophthalmol Vis Sci 2001;42: 2380-2385.

96 Nonaka A, Kiryu J, Tsujikawa A, Yamashiro K, Miyamoto K, Nishiwaki H, Mandai M, Honda Y, Ogura Y: Administration of 17beta-estradiol attenuates retinal ischemia-reperfusion injury in rats. Invest Ophthalmol Vis Sci 2000;41:2689-2696. 
-97 Hiroshiba N, Ogura Y, Nishiwaki H, Miyamoto K, Honda Y: Alterations of retinal microcirculation in response to scatter photocoagulation. Invest Ophthalmol Vis Sci 1998;39:769-776.

$\$ 98$ Nonaka A, Kiryu J, Tsujikawa A, Yamashiro K, Nishijima K, Kamizuru H, Ieki Y, Miyamoto K, Nishiwaki H, Honda Y, Ogura Y: Inflammatory response after scatter laser photocoagulation in nonphotocoagulated retina. Invest Ophthalmol Vis Sci 2002;43: 1204-1209.

-99 Musashi K, Kiryu J, Miyamoto K, Miyahara S, Katsuta H, Tamura H, Hirose F, Yoshimura N: Thrombin inhibitor reduces leukocyte-endothelial cell interactions and vascular leakage after scatter laser photocoagulation. Invest Ophthalmol Vis Sci 2005; 46:2561-2566.

100 Mizuno D, Matsubara A, Ogura Y: Effect of posterior sub-tenon administration of triamcinolone acetonide on leukocyte dynamics in rat retinal microcirculation after panretinal photocoagulation. Invest Ophthalmol Vis Sci 2008;49:2127-2133.

- 101 Unoki N, Nishijima K, Kita M, Suzuma K, Watanabe D, Oh H, Kimura T, Sakamoto A, Yoshimura N: Randomised controlled trial of posterior sub-Tenon triamcinolone as adjunct to panretinal photocoagulation for treatment of diabetic retinopathy. Br J Ophthalmol 2009;93:765-770.

102 Guyer DR, Tiedeman J, Yannuzzi LA, Slakter JS, Parke D, Kelley J, Tang RA, Marmor M, Abrams G, Miller JW, et al: Interferonassociated retinopathy. Arch Ophthalmol 1993;111:350-356.

103 Baarsma GS, van Balen TM: Purtscher's disease. Doc Ophthalmol 1977;44:95-104.

104 Nishiwaki H, Ogura Y, Miyamoto K, Matsuda N, Honda Y: Interferon alfa induces leukocyte capillary trapping in rat retinal microcirculation. Arch Ophthalmol 1996; 114:726-730.

105 Nishiwaki H, Ogura Y, Miyamoto K, Hiroshiba N, Hamada M, Honda Y: Prednisolone, platelet-activating factor receptor antagonist, or superoxide dismutase reduced leukocyte entrapment induced by interferon alpha in retinal microcirculation. Invest Ophthalmol Vis Sci 1997;38:811-816.

106 Miyamoto K, Ogura Y, Hamada M, Nishiwaki $\mathrm{H}$, Hiroshiba $\mathrm{N}$, Honda $\mathrm{Y}$ : In vivo quantification of leukocyte behavior in the retina during endotoxin-induced uveitis. Invest Ophthalmol Vis Sci 1996;37:27082715.
107 Miyamoto K, Ogura Y, Hamada M, Nishiwaki H, Hiroshiba N, Tsujikawa A, Mandai M, Suzuma K, Tojo SJ, Honda Y: In vivo neutralization of P-selectin inhibits leukocyte-endothelial interactions in retinal microcirculation during ocular inflammation. Microvasc Res 1998;55:230-240.

108 Suzuma I, Mandai M, Suzuma K, Ishida K, Tojo SJ, Honda Y: Contribution of E-selectin to cellular infiltration during endotoxin-induced uveitis. Invest Ophthalmol Vis Sci 1998;39:1620-1630.

109 Yamashiro K, Kiryu J, Tsujikawa A, Nonaka A, Nishijima K, Kamizuru H, Miyamoto K, Honda Y, Jomori T, Ogura Y: Suppressive effects of selectin inhibitor SKK-60060 on the leucocyte infiltration during endotoxin induced uveitis. Br J Ophthalmol 2003;87:476-480.

110 Koizumi K, Poulaki V, Doehmen S, Welsandt G, Radetzky S, Lappas A, Kociok N, Kirchhof B, Joussen AM: Contribution of TNF-alpha to leukocyte adhesion, vascular leakage, and apoptotic cell death in endotoxin-induced uveitis in vivo. Invest Ophthalmol Vis Sci 2003;44:2184-2191.

111 Yamashiro K, Kiryu J, Tsujikawa A, Nonaka A, Honjo M, Tanihara H, Nishiwaki $\mathrm{H}$, Honda Y, Ogura Y: Suppressive effects of histamine $\mathrm{H} 1$ receptor antagonist diphenhydramine on the leukocyte infiltration during endotoxin-induced uveitis. Exp Eye Res 2001;73:69-80.

112 Yamashiro K, Kiryu J, Tsujikawa A, Honjo M, Nonaka A, Miyamoto K, Honda Y, Tanihara $\mathrm{H}$, Ogura Y: Inhibitory effects of antithrombin III against leukocyte rolling and infiltration during endotoxin-induced uveitis in rats. Invest Ophthalmol Vis Sci 2001; 42:1553-1560.

113 Hamada M, Ogura Y, Miyamoto K, Nishiwaki $\mathrm{H}$, Hiroshiba N, Honda Y: Retinal leukocyte behavior in experimental autoimmune uveoretinitis of rats. Exp Eye Res 1997;65:445-450.

114 Forrester JV, Liversidge J, Dua HS, Dick A, Harper F, McMenamin PG: Experimental autoimmune uveoretinitis: a model system for immunointervention: a review. Curr Eye Res 1992;11(suppl):33-40.

-115 Wildner G, Diedrichs-Mohring M, Thurau SR: Rat models of autoimmune uveitis. Ophthalmic Res 2008;40:141-144.
116 Almulki L, Noda K, Amini R, Schering A Garland RC, Nakao S, Nakazawa T, Hisatomi T, Thomas KL, Masli S, Hafezi-Moghadam A: Surprising up-regulation of $\mathrm{P}$ selectin glycoprotein ligand-1 (PSGL-1) in endotoxin-induced uveitis. FASEB J 2009; 23:929-939.

$117 \mathrm{Xu} \mathrm{H}$, Cheng CL, Chen M, Manivannan A, Cabay L, Pertwee RG, Coutts A, Forrester JV: Anti-inflammatory property of the cannabinoid receptor-2-selective agonist JWH-133 in a rodent model of autoimmune uveoretinitis. J Leukoc Biol 2007;82:532541.

118 Crane IJ, Xu H, Wallace C, Manivannan A, Mack M, Liversidge J, Marquez G, Sharp PF, Forrester JV: Involvement of CCR5 in the passage of Th1-type cells across the bloodretina barrier in experimental autoimmune uveitis. J Leukoc Biol 2006;79:435-443.

119 Xu H, Manivannan A, Jiang HR, Liversidge J, Sharp PF, Forrester JV, Crane IJ: Recruitment of IFN-gamma-producing (Th1-like) cells into the inflamed retina in vivo is preferentially regulated by $\mathrm{P}$-selectin glycoprotein ligand 1 : $\mathrm{P} / \mathrm{E}$-selectin interactions. J Immunol 2004;172:3215-3224.

120 Honjo M, Nakamura K, Yamashiro K, Kiryu J, Tanihara H, McEvoy LM, Honda Y, Butcher EC, Masaki T, Sawamura T: Lectinlike oxidized LDL receptor-1 is a cell-adhesion molecule involved in endotoxin-induced inflammation. Proc Natl Acad Sci USA 2003;100:1274-1279.

121 Kerr EC, Raveney BJ, Copland DA, Dick AD, Nicholson LB: Analysis of retinal cellular infiltrate in experimental autoimmune uveoretinitis reveals multiple regulatory cell populations. J Autoimmun 2008; 31:354-361.

122 Noda K, Miyahara S, Nakazawa T, Almulki L, Nakao S, Hisatomi T, She H, Thomas KL, Garland RC, Miller JW, Gragoudas ES, Kawai Y, Mashima Y, Hafezi-Moghadam A: Inhibition of vascular adhesion protein-1 suppresses endotoxin-induced uveitis. FASEB J 2008;22:1094-1103.

123 Crane IJ, Liversidge J: Mechanisms of leukocyte migration across the blood-retina barrier. Semin Immunopathol 2008;30: 165-177.

124 Kerr EC, Copland DA, Dick AD, Nicholson LB: The dynamics of leukocyte infiltration in experimental autoimmune uveoretinitis. Prog Retin Eye Res 2008;27:527-535.

125 Caspi RR: Experimental autoimmune uveoretinitis in the rat and mouse. Curr Protoc Immunol 2003; chapter 15:unit 15.6. 